\title{
Coupled Building and System Simulations for Detection and Diagnosis of High District Heating Return Temperatures
}

\author{
Aurélien Brès ${ }^{1}$, Christian Johansson ${ }^{2}$, Roman Geyer ${ }^{1}$, Paolo Leoni ${ }^{1}$, Johan Sjögren ${ }^{3}$ \\ ${ }^{1}$ AIT Austrian Institute of Technology, Vienna, Austria \\ ${ }^{2}$ NODA Intelligent Systems, Karlshamn, Sweden \\ ${ }^{3}$ Neodev AB, Malmö, Sweden
}

\begin{abstract}
High return temperatures are a frequent issue leading to inefficiencies in district heating networks. The causes for high return temperatures usually lie on the secondary side, within the building heating system. However, the district heating operator will in most cases only have access to primary side data through the heat meter. This makes it difficult for the operator to identify and remedy these causes. This contribution uses coupled building and system simulations to investigate issues leading to high return temperatures. The resulting synthetic data replace inaccessible secondary side data for the training of supervised classification algorithms allowing these issues to be diagnosed based on temperature and flow measurements in district heating substations.

These classification algorithms are tested with three cases differing in the assumed availability of secondary side data. Fault detection and diagnosis can be performed with primary data only, with a modest degree of accuracy. Temperature measurements on the secondary side of the substation are shown to considerably improve the quality of predictions, from $78 \%$ to $96 \%$ classification accuracy.
\end{abstract}

\section{Introduction}

High return temperatures are a frequent issue leading to inefficiencies in district heating networks (Gadd, 2014; Zinko et al., 2005). The causes for high return temperatures usually lie on the secondary (customer) side. Traditionally, district heating operators only have access to hardware and data on the primary side and not on the secondary side. This makes the causes for high return temperatures difficult for operators to identify and remedy. This paper presents the simulations developed to investigate four possible issues potentially leading to high return temperatures. The aim is to use the results of a large number of simulations to discover the "signature" of respective faults in time series of measurable physical values. Despite high return temperatures being a specific district heating issue, related work can be found in fault detection and diagnosis (FDD) for building systems.
This paper investigates the hypothesis that building performance simulation has the potential to assess a variety of issues in terms of their impact on return temperatures and, further, to generate data for the training of FDD algorithms. After a review of related work in these domains, a simulation-based method for the investigation of high district heating return temperatures is presented. The method is then applied to a case study, followed by a discussion of the results.

\section{Related work}

\section{District heating return temperatures}

District heating (DH) systems supply heat generated in centralized locations to consumers located in multiple buildings, connecting these sources and consumers through a pipe network (Frederiksen and Werner, 2013). Benefits of this centralized heat supply include its flexibility, the lower costs and higher efficiency of heat generation in larger units, as well as the possibility to utilize excess heat and other forms of renewable heat sources (Zinko et al., 2005). Renewable heat sources are often at a lower temperature than used in traditional DH systems, which is why a transition towards lower temperature levels makes an increasing share of renewable energy in $\mathrm{DH}$ possible (Lund et al., 2014; Brand, 2014). In practice, return temperatures higher than planned have been recognized to be a frequent issue hampering efficient and cost-effective operation of district heating (Zinko et al., 2005). While primary supply temperatures are under the control of district heating operators, return temperatures depend on the cooling taking place on the secondary side, which may be insufficient for a variety of reasons. Causes for high return temperatures may differ in their origin, temporal behaviour, location in the system, and impact. The issue may lie in the substation heat exchanger, or in the customer heating system and its controls, or even in occupant behavior (Geyer and Schmidt, 2017). The issue of return temperatures in district heating systems has already been tackled in an IEA project, where the concepts of excess flow and target return temperatures were used to detect malfunctioning substations (Zinko et al., 2005). Diagnosis 
was limited to reasoning on the time $\mathrm{o}$ malfunctions arised, and concluding w] was related to space heating or dome Whereas in the past meter readings in were usually performed manually for $b$ they are starting to be available at a tion, which offers the possibility to $\mathrm{d} t$ behavior in a proactive and affordab 2014). Gadd and Werner (2015) used in 135 Swedish district heating substat three main types of faults. They founc than two thirds of the substations. T] done manually, but the possibility of was highlighted.

\section{Fault detection and diagnosis in tems}

Automated fault detection and diagnc ventilation and air-conditioning $(\mathrm{HV} t$ an active area of research, with a wide ods. In an extensive review of such and Katipamula (2018) categorized the whether they are based on process hist models or quantitative models. The $\mathrm{m}$. the use of model-based methods is the ating the models and validating them data. Generally, FDD research has oft on particular components, with a con of research on FDD for chillers and airbut approaches looking at the whole also been proposed (Kim and Katipam such cases, it can be argued that b mance simulation is the soundest way impact of faults taking into account in various levels (Zhang and Hong, 2017.

\section{Building and HVAC simulation}

To model the impact of faults resultin trict heating return temperatures, ont sider temperatures supplied by distri works, substations, customer heating $\mathrm{s}$ buildings they serve. Existing simul low models accounting for the interplay systems to be executed and provide $\mathrm{c}$ formation on the resulting behavior.

Whole building thermal simulation $\mathrm{m}$. nature of the link between inputs and . box versus white-box models), in the $\mathrm{t}$ ] temporal dimension (stationary versus els) and in the level of detail in which $d$ are modelled (de Wilde, 2018). In t structure, approaches for the simulatio tems range from conceptual models ir behavior is completely idealized to co: and equation-based models (Trčka and Hensen, 2010). In the present research, component-based modeling of heating systems is assumed to be a suitable level of detail. Faults affecting specific components are best modelled if the corresponding components are

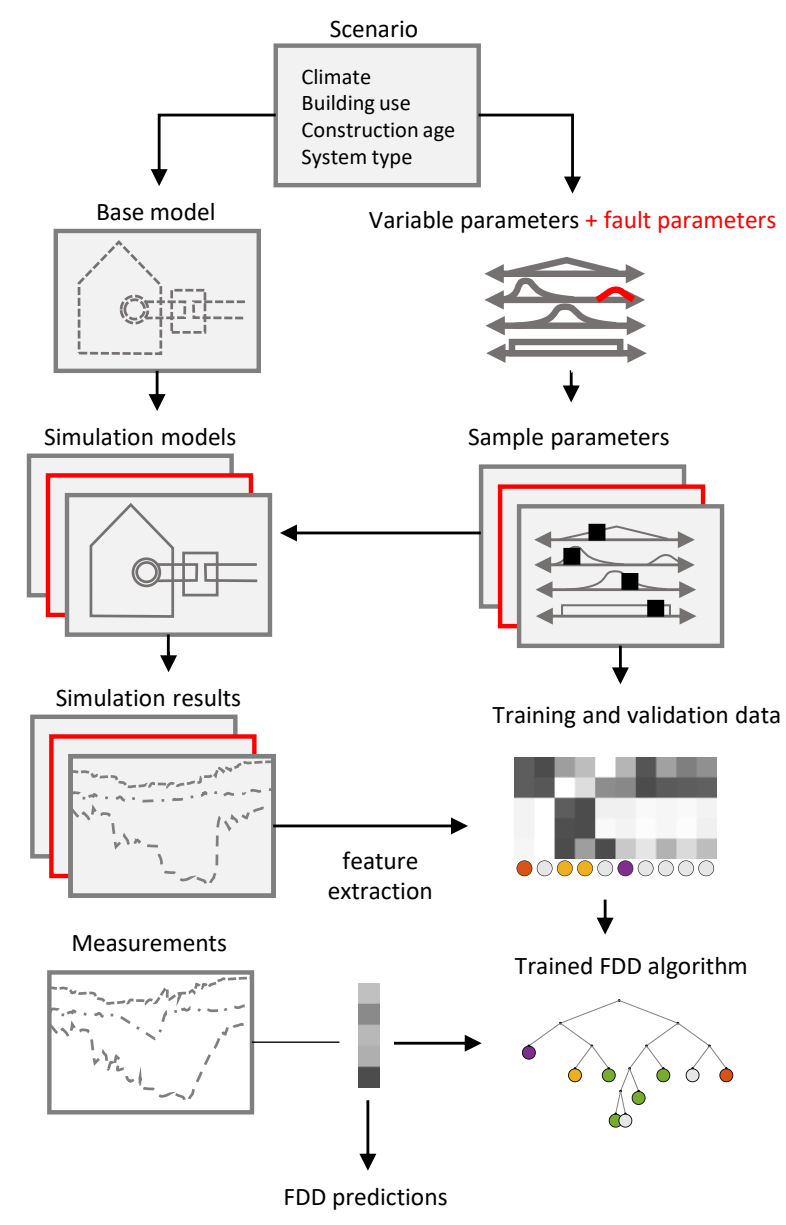

Figure 1: Proposed method.

explicitly modelled. On the other hand, more detailed equation-based modeling may provide more accurate results and make it possible to simulate additional issues, such as hydraulic imbalance. However, the additional computing effort may be problematic considering the high number of simulation runs, and parameter setting would be more challenging.

\section{Method}

\section{Overview}

The objective of the proposed method is to model issues affecting district heating substations and customer heating systems, so as to discover "signatures" allowing to detect and diagnose these issues in measurable time series. For the corresponding fault detection and diagnosis to be robust, the simulation models used to generate data need to account for the variability of conditions and parameters which may affect substation behavior.

An overview of the proposed method is illustrated in Figure 1. The method is applied to specific scenarios, each of which corresponds to a certain type of building and system, with similar climate and construction quality. For each scenario, a model structure is defined, as well as variable parameters with specific ranges, and faults, which may also be defined parametrically. 
Simulation experiments are then carried out by sampling sets of values for the variable parameters. These sets of values correspond to cases with faults, but also (mostly) without faults. A simulation model is then created and run for each set of value. The corresponding results represent the data used to train fault detection and diagnosis algorithms.

\section{Modeling approach}

For each scenario, a base simulation model is prepared, as well as a list of variable parameters and their ranges. The simulation model should be detailed and flexible enough to evaluate normal operation and faults. For the implementation of the method presented here, coupled simulation is carried out with EnergyPlus and TRNSYS (Crawley et al., 2001; Klein, 1988). TRNSYS is used to model the heating systems, and EnergyPlus for the building behavior. These two tools are used so as to take advantage of the superior flexibility and level of detail of each tool for the respective domain. Run-time coupling is implemented with the functional Mock-up interface (FMI) (Nouidui et al., 2014). The componentbased TRNSYS system model, illustrated in Figure 3 , includes delivery components for each zone, distribution components (pumps, pipes and valves) and substation heat exchangers, as well as a heat source representing the district heating network itself, with a supply temperature varying as a function of outdoor temperature. It takes zone temperatures as inputs and returns delivered heat rates as outputs. The EnergyPlus building model, for which inputs and outputs are reversed, has a given base geometry for each scenario, but is subject to variations in window-towall ratio construction properties, internal loads, infiltration and weather.

\section{Simulation model preparation}

As the method relies upon a large number of simulations, a high degree of automation in preparing and running the models is essential to its applicability. A key task is the sizing of system components, which should be realistic and at the same time account for a certain sizing variability, including also possible faults. This sizing is carried out programmatically with the successive application of procedures dealing with subsystems from the demand to the supply side, as in Bres (2018). This starts with the calculation of design heat loads from building model and construction properties. Using design temperatures as variable inputs, delivery components are then determined and sized for each zone, followed by an approximation of the secondary distribution subsystems and by the substation and its heat exchanger. Sizing variability is introduced with sizing factors applied at different steps (parameters 14 and 20 in Table 1).

Different types of faults are introduced in the model in various ways. Design faults are modelled with the use of faulty sizing values (e.g. fault 4 in Table 2 ) in the procedures mentioned above. Models of normallyfunctioning systems obtained from the previous procedures are partially modified to account for operation faults (e.g. fault 3 in Table 2). Control faults (e.g. faults 1 and 2 in Table 2) can be introduced by modifying control parameters.

\section{Sampling approach}

In order to use simulation data to train robust fault detection and diagnosis algorithms, it should reflect the variability of properties and conditions affecting system behavior. This should be ensured by an appropriate design of experiments, allowing the parameter space to be explored in an efficient way. To this aim, a Latin hypercube design is used for sampling input variables (Levy and Steinberg, 2010). Also, in order to account for the variability of occupant behavior, a stochastic approach is used to generate different occupancy and tap water draw profiles for each simulation run, following Page et al. (2008) and Fischer et al. (2016).

After sampling $n$ points with values from the regular ranges, faults are introduced by modifying certain values in some of these points.

\section{Analysis and algorithm training}

The results of simulations prepared and run for each of the previously defined $n$ points are finally analysed and used for fault detection and diagnosis. This includes the calculation of indicators for each simulation, the analysis of input-output relationships based on these indicators, and eventually the training and validation of automated FDD algorithms.

Simulation results and substation performance are assessed with a variety of indicators, a selection of which is summarized in Table 3. Volume-weighted average primary return temperature can be considered to best represent the impact of substation return temperatures for the network (Crane, 2016).

Excluding cases of substations with more than one fault, fault detection and diagnosis can be formulated as a classification problem with classes corresponding to different faults and to the fault-free case. The aim is to predict the right class based on measurable quantities. In this stage, it was decided to transform the time series by calculating statistics over the full simulation period and to use these as features for the classification algorithms. More specifically, let $\left(x_{i}^{(j)}\right)_{1 \leqslant i \leqslant t, 1 \leqslant i \leqslant m}$ be the values of $m$ measurable quantities for $t$ time steps. These measurable quantities correspond to temperatures and flow rates. For each pair $\left(j_{1}, j_{2}\right)$ of these measurable quantities, we calculate the following statistics: correlation coefficient $\rho_{x^{\left(j_{1}\right)}, x^{\left(j_{2}\right)}}$ and quotient of average values $\frac{\overline{x^{\left(j_{1}\right)}}}{x^{\left(j_{2}\right)}}$. The corresponding values are then used for the training of classification algorithms, starting with binary decision trees. 


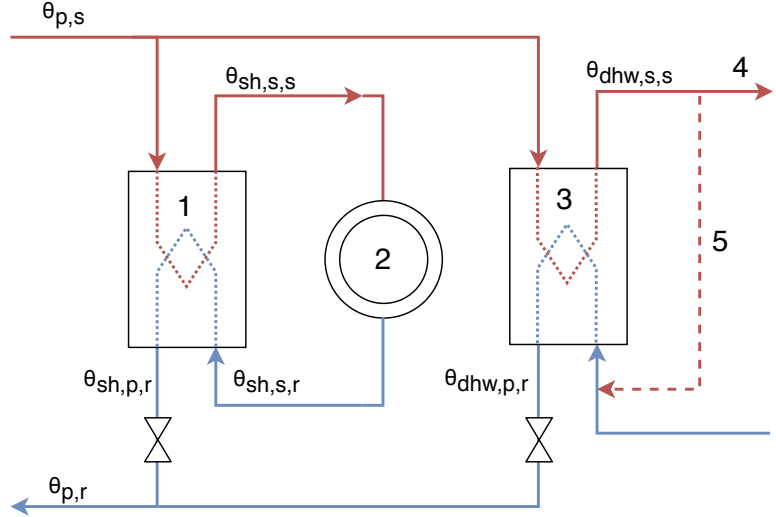

Figure 2: Layout of the substation for the case study. 1: heat exchanger for space heating. 2: space heating consumers (radiator heating). 3: heat exchanger for domestic hot water. 4: domestic hot water consumer. 5: domestic hot water recirculation.

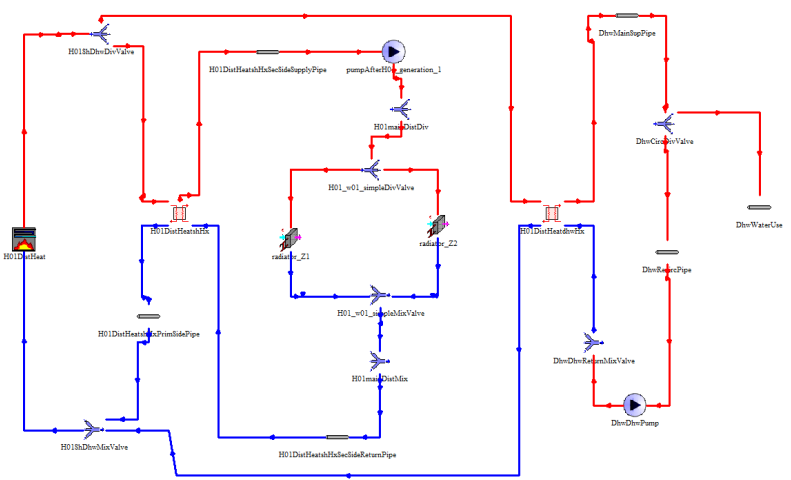

Figure 3: TRNSYS model components of the substation and heating system. For clarity, only physical components are shown, while control and data flow units are hidden.

\section{Case study}

\section{Scenario}

The method proposed in this paper is illustrated with a case study corresponding to a single scenario. The scenario corresponds to single-family houses built in the 1980's and 1990's in Northern Germany. The houses are supplied with district heating for space heating and domestic hot water, using an indirect parallel connection as illustrated in Figure 2. Variable simulation input parameters with the value ranges corresponding to this scenario are summarized in Table 1. Four types of faults are selected for simulation, as summarized in Table 2.

\section{Simulation results}

The previously described method is applied to this scenario generating $n=1000$ simulations, for a sixmonth simulation period. A time step of 10 minutes is chosen, for reasons of simulation stability and because it corresponds to the short end of monitoring intervals used in practice. Each of the four fault types is introduced in $10 \%$ of the simulations, yielding a total

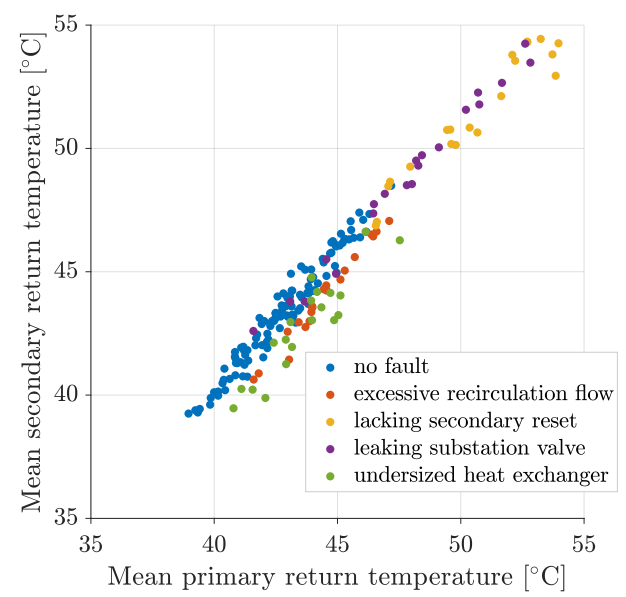

Figure 4: Scatter plot of averaged secondary and primary return temperatures for 200 simulations.

of $40 \%$ simulation runs with faults and $60 \%$ fault-free simulation runs.

The simulation data is reduced to a smaller set of significant numbers by calculating summary indicators for each simulation run. Figure 4 shows average primary and secondary space heating return temperatures for each simulation run. A trend for higher return temperatures in the case of faults can be distinguished, but it is not sufficient for accurate fault detection. Primary return temperatures are also dependent on primary supply temperature, which represents a confounding variable not related to substation and secondary systems.

The impact of the simulation parameter settings on the indicators summarized in Table 3 are reviewed by multiple linear regression. Figure 5 shows resulting coefficients for a selection of independent (simulation input parameters) and dependent (simulation output indicators) variables. This allows the various impacts of variable parameters - whether related to faults or not - to be visualized and compared. A key indicator for the present work is mean primary return temperature (mprt). Particularly noticeable for this indicator are the strong impacts of the heat curve parameter (19) and the leakage rate parameter (13), which are related to two faults, but also that of the design secondary supply temperature (15), which we consider to vary in a certain range $\left(55\right.$ to $\left.65^{\circ} \mathrm{C}\right)$ independently of faults. Conversely, a parameter like the temperature set point chosen by occupants (4) has a high impact on energy consumption but not on return temperatures. 
Table 1: Variable simulation input parameters with their value ranges in the normal case and, where applicable, in fault cases.

\begin{tabular}{|c|c|c|c|c|}
\hline Parameter & Min & Max & Unit & Fault values \\
\hline 1 - window U-value & 1.0 & 2.0 & $\mathrm{~W} /\left(\mathrm{m}^{2} \mathrm{~K}\right)$ & \\
\hline 2 - wall U-value & 0.4 & 0.8 & $\mathrm{~W} /\left(\mathrm{m}^{2} \mathrm{~K}\right)$ & \\
\hline 3 - window g-value & 0.5 & 0.7 & & \\
\hline 4 - occupant-defined heating set point & 19 & 23 & ${ }^{\circ} \mathrm{C}$ & \\
\hline 5 - heat gain from electric equipment & 5 & 11 & $\mathrm{~W} / \mathrm{m}^{2}$ & \\
\hline 6 - area per person & 15 & 45 & $\mathrm{~m}^{2} /$ person & \\
\hline 7 - ventilation per area & 1.0 & 2.0 & $\mathrm{~m}^{3} /(\mathrm{h} \mathrm{m} 2)$ & \\
\hline 8 - infiltration rate & 0.1 & 0.2 & $h^{-1}$ & \\
\hline 9 - infiltration coefficient a & 0.5 & 0.8 & & \\
\hline 10 - infiltration coefficient $b$ & 0.02 & 0.04 & $\mathrm{~K}^{-1}$ & \\
\hline 11 - weather constant temperature shift & -2 & 2 & ${ }^{\circ} \mathrm{C}$ & \\
\hline 12 - window-to-wall ratio & 0.15 & 0.35 & & \\
\hline 13 - space heating heat exchanger valve leakage rate & 0.001 & 0.003 & & 0.2 to 0.3 \\
\hline 14 - design $\Delta \theta$ primary - secondary return & 1.0 & 1.5 & $\mathrm{~K}$ & 4.0 to 6.0 \\
\hline 15 - design temperature from generation subsystem & 55 & 65 & ${ }^{\circ} \mathrm{C}$ & \\
\hline 16 - secondary heating curve: $\mathrm{x} 1$ & -15 & -5 & ${ }^{\circ} \mathrm{C}$ & \\
\hline 17 - secondary heating curve: $x 2$ & 10 & 16 & ${ }^{\circ} \mathrm{C}$ & \\
\hline 18 - secondary heating curve: averaging time & 0 & 4 & $\mathrm{~h}$ & \\
\hline 19 - secondary heating curve: y2 & 40 & 50 & ${ }^{\circ} \mathrm{C}$ & $=$ parameter 15 \\
\hline 20 - delivery sizing factor & 1.0 & 1.2 & & \\
\hline 21 - delivery PID control: constant term & 0.05 & 0.15 & & \\
\hline 22 - delivery PID control: integral term & 0.5 & 1.5 & & \\
\hline 23 - primary supply temperature curve: $\mathrm{x} 1$ & -25 & -15 & ${ }^{\circ} \mathrm{C}$ & \\
\hline 24 - primary supply temperature curve: $\mathrm{x} 2$ & 8 & 12 & ${ }^{\circ} \mathrm{C}$ & \\
\hline 25 - primary supply temperature curve: y1 & 90 & 110 & ${ }^{\circ} \mathrm{C}$ & \\
\hline 26 - primary supply temperature curve: y2 & 65 & 85 & ${ }^{\circ} \mathrm{C}$ & \\
\hline 27 - space heating heat exchanger PID controller: $K_{p}$ & 0.002 & 0.004 & & \\
\hline 28 - space heating heat exchanger PID controller: $T_{i}$ & 0.05 & 0.15 & $\mathrm{~h}$ & \\
\hline 29 - pipe insulation factor & 0.3 & 0.5 & & \\
\hline 30 - recirculation control temperature difference & 4.5 & 5.5 & & 2 to 3 \\
\hline
\end{tabular}

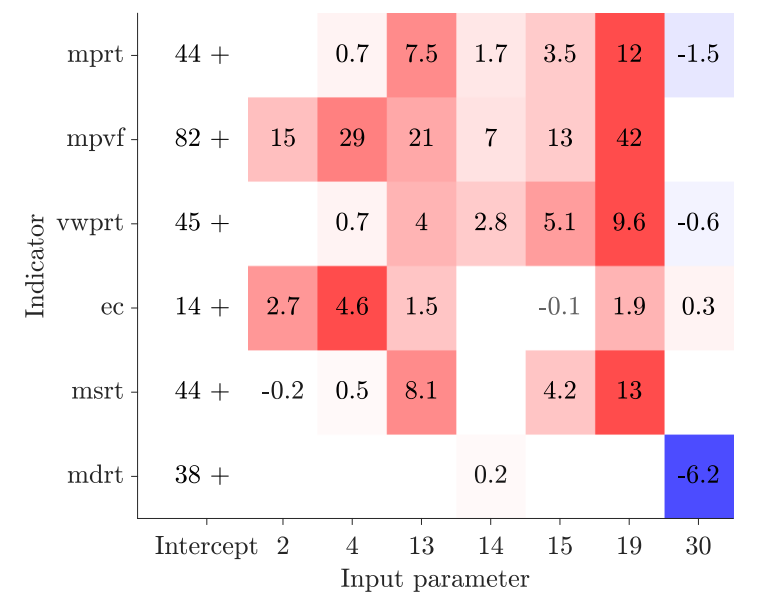

Figure 5: Regression coefficients for selected input variables (as in Table 1, 7 of 30 independent variables) and indicators (dependent variables) as in Table 3: red for positive coefficients, blue for negative coefficients. Only values of relevant coefficients ( $p$ value under 0.05) are written.
Table 2: Modelled faults and corresponding parameter IDs (as in Table 1).

\begin{tabular}{|l|c|}
\hline Fault & Parameter \\
\hline $\begin{array}{l}1-\text { excessive hot water recirculation } \\
\text { flow }\end{array}$ & 30 \\
\hline $\begin{array}{l}2 \text { - lacking space heating secondary } \\
\text { temperature reset }\end{array}$ & 19 \\
\hline $\begin{array}{l}3 \text { - leaking space heating heat ex- } \\
\text { changer valve }\end{array}$ & 13 \\
\hline $\begin{array}{l}4-\text { undersized space heating heat ex- } \\
\text { changer }\end{array}$ & 14 \\
\hline
\end{tabular}

\section{Fault detection and diagnosis}

The next step is to transform simulation results into features for classification. We distinguish three cases for the selection of $m$ measurable quantities among simulation results, corresponding to measurements which are assumed to be available:

- A: only primary supply and return temperatures, primary flow rate and ambient temperature are available $(m=4)$.

- B: in addition to $\mathrm{A}$, temperature measurements on the secondary side are available $(m=8)$.

- $\mathrm{C}$ : in addition to $\mathrm{B}$, flow rates on the secondary side are available $(m=10)$. 
Table 3: Simulation output indicators.

\begin{tabular}{|c|c|c|}
\hline ID & Indicator & Unit \\
\hline mprt & $\begin{array}{l}\text { mean primary return tem- } \\
\text { perature }\end{array}$ & $\bar{\circ} \mathrm{C}$ \\
\hline $\begin{array}{l}\text { mpvf } \\
\text { vwprt }\end{array}$ & $\begin{array}{l}\text { mean primary volume flow } \\
\text { volume-weighted primary }\end{array}$ & $\begin{array}{c}\mathrm{m}^{3} / \mathrm{h} \\
{ }^{\circ} \mathrm{C}\end{array}$ \\
\hline $\begin{array}{c}\text { ec } \\
\text { msrt }\end{array}$ & $\begin{array}{l}\text { energy consumption } \\
\text { mean secondary return tem- } \\
\text { perature }\end{array}$ & $\begin{array}{l}\mathrm{MWh} \\
{ }^{\circ} \mathrm{C}\end{array}$ \\
\hline mdrt & $\begin{array}{l}\text { mean DHW return temper- } \\
\text { ature }\end{array}$ & ${ }^{\circ} \mathrm{C}$ \\
\hline
\end{tabular}

Using pairwise correlation coefficients and quotients of means as indicated above, the resulting number of features is equal to $m(m-1)$ : 12 for case A, 56 for case $\mathrm{B}$ and 90 for case $\mathrm{C}$. The results shown in the following are obtained by calculating features directly from the raw simulation results (time steps of 10 minutes). Averaging simulation results to hourly values before feature calculation was found to yield similar results, not shown in this paper.

As a classification method, we use binary decision trees (Kotsiantis et al., 2007; Reddy, 2011) obtained with the classification and regression tree (CART) algorithm (Breiman et al., 1984; Steinberg and Colla, 2009) as implemented in MATLAB. The choice of decision trees was mainly motivated by their ease of interpretation and low number of hyperparameters. The resulting classification performance is evaluated with five-fold cross-validation.

Results of classification for the three cases are summarized in Figure 6. Calculating the overall accuracy as the number of correct predictions divided by the total number of predictions, the values obtained for cases $\mathrm{A}, \mathrm{B}$ and $\mathrm{C}$ are $78 \%, 96 \%$ and $96 \%$, respectively. Thus, very good results are obtained in cases B and C. Weaker performance is noticeable for fault 4 (undersized heat exchanger), with $30 \%$ of false negatives and $20 \%$ of false positives, while the other three faults are diagnosed with 95 to $100 \%$ accuracy.

The results obtained with primary measurements only, displayed in Figure 6a, are significantly inferior. While predictions for fault 3 are still accurate, the number of false negatives and false positives for the other faults is high.

\section{Discussion}

The presented case study shows that the modelled faults indeed exhibit signatures: given the right measurements, it is possible to detect and diagnose them with good accuracy when measurements on both primary and secondary sides are available. As could be expected, $100 \%$ accuracy is not achieved, but this should not prevent the method from being helpful in directing attention to possible reasons for high return temperatures.

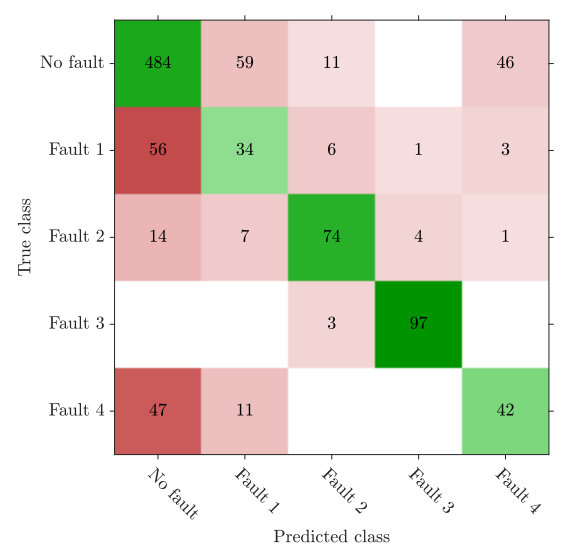

(a) Case A.

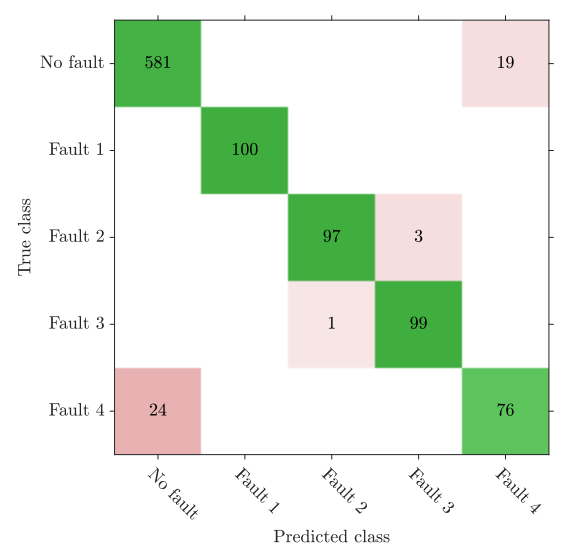

(b) Case B.

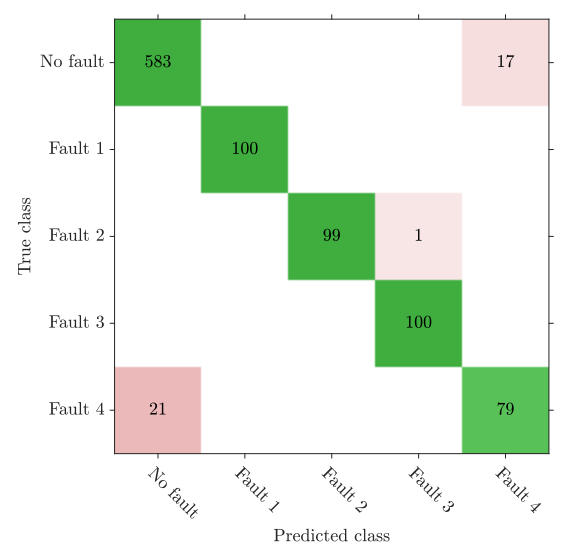

(c) Case $C$.

Figure 6: Confusion matrices showing the number of true predictions in green and false predictions in red for classification in the three cases of measurement availability. 
The analysis of simulation results shows that the boundary between faults and normal variations is often blurry. For instance, it was assumed for the present case study that the design supply temperature varies in a certain range, without considering it a fault. It can be seen in the results that these variations have a significant impact, such that one may also consider it a fault ("excessively high design temperature").

Validation of the proposed method and the simulations underlying it deserves further discussion. A possible starting point is to distinguish between different sources of uncertainty (Macdonald, 2002):

- model inadequacy should be kept low. Component models are validated to a large extent, but the adequacy of their combination in a whole model can be questioned.

- parameter uncertainty should have limited impact, as we use parameter ranges and look at correlations and differences between outputs rather than at absolute values. However, parameter ranges for each scenario should also be validated, and may need to be refined.

- residual variability (including stochastic processes) is partially represented in the model and covered by parameter variations.

- code uncertainty is assumed to be reasonably low, as the simulation tools we use have been subject to validation.

Several efforts have been used for quality control of the simulations:

- Results of single simulation runs have been checked for plausibility, using a variety of plots making a qualitative comparison with measured cases possible.

- Condensing the results of simulations in indicators allows abnormal behavior to be detected quickly for simulation batches. For instance, it is checked whether excessive oscillations are present in simulation results.

- Trained classification trees are checked for plausibility by looking at the features used for diagnosing each fault.

The next step will be empirical validation of the simulation data with real-life operational data. Ultimately, validating the proposed method would require the use of the trained classification algorithms on real data. The resulting predictions should be compared with the outcome of detailed system audits which would allow the corresponding faults to be identified.

The results of the case study show the accuracy of predictions to be dependent on the availability of measurements on the secondary side. Compared with case A in which only primary measurements are available, temperature measurements on the secondary side (case B) make considerable accuracy improvements possible. By comparison, the added value of additional flow rate measurements on the secondary side (case C) appears to be very low. Given the cost of such flow rate measurements, case $\mathrm{C}$ does not appear to be practically motivated.

\section{Conclusion}

The present work addressed the issue of higher-thanplanned return temperatures in district heating networks, with focus on the customer side. These may be caused by a number of reasons, which we can refer to as "faults". Coupled building and system simulation can be used to model the dynamic behavior of buildings and heating systems served by district heating, and the way it is affected by faults. By running a sufficient number of such simulations, training data can be produced for fault detection and diagnosis algorithms.

The application of classification algorithms to simulation data gives promising results. A distinctive contribution of this paper is that it quantifies the value of using temperature measurements on the secondary side. It shows that these measurements make it possible to go beyond fault identification and perform fault diagnosis with good accuracy. Conversely, additional flow rate measurements on the secondary side are shown to be superfluous. The results also show that certain faults are easier to diagnose than others.

The application of the method may contribute to the optimization of district heating systems and their transformation towards fourth generation district heating systems with a higher share of renewable energies. Future work in this direction should include the modeling of additional types of faults and validation work with real systems. Fault diagnosis accuracy can be expected to decrease with a higher number of fault types. On the other hand, classification results may be improved by using other features and other algorithms than classification trees. Results are also expected to depend on the length and resolution of time series, which should also be investigated. Calculating statistics in a sliding window fashion rather than for the whole simulation period may allow the method to be applied for continuous delivery.

\section{Acknowledgment}

This research was performed within the TEMPO project, funded by the European Union's Horizon 2020 research and innovation programme under grant agreement No 768936.

\section{References}

Brand, M. (2014). Heating and Domestic Hot Water Systems in Buildings Supplied by Low-Temperature District Heating. Ph. D. thesis, Technical University of Denmark. 
Breiman, L., J. Friedman, R. Olshen, and C. Stone (1984). Classification and Regression Trees. Wadsworth.

Bres, A. (2018). Automated model generation for integrated building and HVAC performance simulation. Ph. D. thesis, Vienna University of Technology.

Crane, M. (2016). Individual apartment substation testing - Development of a test and initial results. In The 15th International Symposium on District Heating and Cooling.

Crawley, D. B., L. K. Lawrie, F. C. Winkelmann, W. F. Buhl, Y. J. Huang, C. O. Pedersen, R. K. Strand, R. J. Liesen, D. E. Fisher, M. J. Witte, and Others (2001). EnergyPlus: creating a newgeneration building energy simulation program. Energy and buildings 33(4), 319-331.

de Wilde, P. (2018). Building Performance Analysis. Wiley-Blackwell.

Fischer, D., T. Wolf, J. Scherer, and B. WilleHaussmann (2016). A stochastic bottom-up model for space heating and domestic hot water load profiles for german households. Energy and Buildings 124, 120-128.

Frederiksen, S. and S. Werner (2013). District Heating and Cooling. Studentlitteratur AB.

Gadd, H. (2014). To analyse measurements is to know! - Analysis of hourly meter readings in district heating systems. Ph. D. thesis, Lund University.

Gadd, H. and S. Werner (2015). Fault detection in district heating substations. Applied Energy 15\%, 51-59.

Geyer, R. and R.-R. Schmidt (2017). Vorsicht heiß - Ursachen hoher Rücklauftemperaturen in Fernwärmenetzen. EuroHeat\&PPower (11), 50-53.

Kim, W. and S. Katipamula (2018). A review of fault detection and diagnostics methods for building systems. Science and Technology for the Built Environment 24(1), 3-21.

Klein, S. A. (1988). Trnsys - a transient system simulation program. University of Wisconsin-Madison, Engineering Experiment Station Report.

Kotsiantis, S. B., I. Zaharakis, and P. Pintelas (2007). Supervised machine learning: A review of classification techniques. Emerging artificial intelligence applications in computer engineering 160, 3-24.

Levy, S. and D. M. Steinberg (2010). Computer experiments: a review. Advances in Statistical Analysis $94(4), 311-324$.
Lund, H., S. Werner, R. Wiltshire, S. Svendsen, J. E. Thorsen, F. Hvelplund, and B. V. Mathiesen (2014). 4th generation district heating (4gdh): Integrating smart thermal grids into future sustainable energy systems. Energy 68, 1-11.

Macdonald, I. A. (2002). Quantifying the effects of uncertainty in building simulation. Ph. D. thesis, University of Strathclyde.

Nouidui, T., M. Wetter, and W. Zuo (2014). Functional mock-up unit for co-simulation import in EnergyPlus. Journal of Building Performance Simulation 7(3), 192-202.

Page, J., D. Robinson, N. Morel, and J.-L. Scartezzini (2008). A generalised stochastic model for the simulation of occupant presence. Energy and buildings 40(2), 83-98.

Reddy, T. A. (2011). Classification and clustering methods. In T. A. Reddy (Ed), Applied Data Analysis and Modeling for Energy Engineers and Scientists. Springer.

Steinberg, D. and P. Colla (2009). CART: classification and regression trees. In The top ten algorithms in data mining, Chapter 9, pp. 179. CRC Press Boca Raton, FL.

Trčka, M. and J. L. M. Hensen (2010). Overview of HVAC system simulation. Automation in Construction 19(2), 93-99.

Zhang, R. and T. Hong (2017). Modeling of HVAC operational faults in building performance simulation. Applied Energy 202, 178-188.

Zinko, H., L. Hoon, K. Bong-Kyun, K. Youn-Hong, H. Lindkvist, A. Loewen, H. Seungkyu, H. Walletun, and M. Wigbels (2005). Improvement of operational temperature differences in district heating systems. Report of the IEA R\&D Programme on District Heating and Cooling. 